\title{
ESPACIALIDADE URBANA E USOS E APROPRIAÇÕES DE ESPAÇOS PÚBLICOS: ESTUDO DE DUAS PRAÇAS NA CIDADE DO RIO DE JANEIRO \\ URBAN SPACE AND USES AND APPROPRIATIONS OF PUBLIC AREAS: STUDY OF TWO PRACTICES IN THE CITY OF RIO DE JANEIRO
}

\author{
Maria Josefina Gabriel Sant'Anna ${ }^{1}$, Sandra de Sá Carneiro ${ }^{1}$ \\ ${ }^{1}$ Universidade do Estado do Rio de Janeiro (UERJ), Rio de Janeiro,RJ, Brasil
}

Correspondência para: Maria Josefina Gabriel Sant'Anna (maseanna@gmail.com)

doi: 10.12957/geouerj.2017.32059

Recebido em: 1 nov. 2017 | Aceito em: 12 dez. 2017

\section{RESUMO}

O artigo aborda aspectos da dinâmica socioespacial da cidade do Rio de Janeiro. Focaliza os usos e apropriação de espaços públicos, em duas Praças, com diferentes inserções espaciais na cidade: as Praças da Harmonia (Gamboa) e a Mauricio Cardoso (Olaria). Adota-se como pressuposto, que a presença de grupos culturais e mais recentemente de coletivos culturais nos espaços públicos conferem sentido a esses locais como lugares de encontro, de acontecimentos, de sociabilidades, de práticas sociais, de manifestações da vida urbana cotidiana. Entende-se que estas novas modalidades de atuar e de transmutar o espaço ampliam o repertório de leituras possíveis sobre os espaços públicos. Propõe-se que a localização diferenciada de cada uma das Praças no espaço da cidade, conduz lógicas espaciais distintas, e que as singularidades de cada lugar desenham-se segundo suas características locais.

Palavras-chave: dinâmica socioespacial, espaço público, praça, sociabilidade, grupos culturais.

\begin{abstract}
This work focus on the socio-spatial dynamics of Rio de Janeiro city, considering uses and appropriations of public spaces in two squares with different spatial insertions in the city: Harmonia Square (Gamboa district) and Mauricio Cardoso Square (Olaria district). Our assumption is that the presence of cultural groups and, more recently cultural collectives in the public spaces gives to these places the attribute of gathering places for people, improving sociability, social practices, and allowing manifestations of the everyday urban life. We understand that these new modalities of using and changing the space expand the repertoire of readings on public spaces. The different spatial location of the two squares in the city lead to different spatial logics and the singularities of each place expose their local characteristics.
\end{abstract}

Keywords: socio-spatial dynamics, public space, squares, sociability, cultural groups.

\section{INTRODUÇÃO}

\footnotetext{
"Assim como a cidadania e cultura formam um par integrado de significações, assim também cultura e territorialidade são, de certo modo, sinônimas. A cultura, forma de comunicação do indivíduo e do grupo com o universo, é uma herança, mas também um aprendizado das relações profundas entre o homem e o seu meio, um resultado obtido por intermédio do próprio processo de viver."

Milton Santos ${ }^{1}$
}

\footnotetext{
${ }^{1}$ Santos, M. (2007).

(C) 2017 Sant'Anna e Carneiro. Este é um artigo de acesso aberto distribuído sob os termos da Licença Creative Commons AtribuiçãoNão Comercial-Compartilha Igual (CC BY-NC-SA 4.0), que permite uso, distribuição e reprodução para fins não comercias, com a citação dos autores e da fonte original e sob a mesma licença.
} 
O presente artigo discute aspectos da dinâmica socioespacial da cidade do Rio de Janeiro, ao focalizar, numa ótica comparativa, duas experiências de uso e de apropriação do espaço público, em Praças com diferentes inserções espaciais na cidade do Rio de Janeiro: a Praça da Harmonia (Zona Portuária/Gamboa) e a Praça Mauricio Cardoso (Zona Norte/ Olaria). Graças a essa inserção espacial diferenciada é possível evidenciar distintas situações vivenciadas em cada uma das Praças, conferindolhes singularidades próprias.

De início, o interesse da pesquisa direcionou-se principalmente para a discussão sobre os impactos econômicos e espaciais das obras de urbanização em curso na cidade do Rio de Janeiro desde 2009, e sua repercussão na vida cotidiana dos moradores. Sem deixar de lado esse enfoque, pouco a pouco, voltou-se a atenção para os processos de apropriação de usos gerados pelos atores sociais usuários das Praças, verificando como esses constroem suas estratégias dentro e fora desses lugares.

Interessa aqui refletir sobre as ações e atuações de grupos culturais que propõem novas formas de conceber os espaços públicos e novas alternativas para seu usos, a partir da ideia de direito à cidade, em resposta às contradições geradas pelo urbanismo imposto pelo poder público, ao pensar a cidade com uma lógica derivada dos interesses do capital.

Como apontado por diferentes estudiosos, vemos surgir, principalmente a partir dos anos 2000, diversos movimentos sociais que incentivam a ocupação dos espaços públicos. Alguns desses grupos têm recebido a denominação de coletivos urbanos e, como indicam alguns estudos, eles surgem para questionar as condições sociais em que se encontram determinadas áreas/regiões da cidade, tendo como suporte a realização de manifestações de caráter artístico, político e urbanístico.

A forma de organização dos coletivos culturais, como destaca Holanda ${ }^{2}$, é singular em face de outras formas como ONGs, cooperativas, grupos sociais; não é hierárquica e é nômade, o que os diferencia de outros grupos organizados no campo das artes. Não têm número de participantes determinado, nem podem ser caracterizados como movimentos artísticos.

${ }^{2}$ Disponível em: http://www.heloisabuarquedehollanda.com.br/coletivos. Acesso em 22/07/2017. 
São formados apenas em função da produção de um ou mais projetos. Estruturam-se para aquele fim específico e em seguida se recompõem com novos participantes em função de um outro projeto. Isso quer dizer que a composição de um coletivo não é fixa. É móvel. Um artista pode pertencer a um coletivo em função de um projeto e no projeto seguinte juntar-se a outro coletivo para a realização de um outro projeto.

(http://www.heloisabuarquedehollanda.com.br/coletivos)

Desse modo, esses grupos adotam diferentes estratégias sejam artísticas, culturais e políticas, como forma de ativar a vida urbana em suas múltiplas dimensões, questionando, assim, o caráter centralizador com que são conduzidas as políticas públicas voltadas para a dimensão mais lúdica da cidade. Importa perceber que estas formas coletivas de ação derivam de um conjunto de contradições manifestas no espaço físico e existencial das cidades, trazendo formas criativas de novos usos para os espaços em sua dimensão coletiva. Parte-se da premissa de que estas novas modalidades de atuar e de transmutar o espaço ampliam o repertório de leituras possíveis sobre os territórios.

Entende-se a princípio que esses coletivos estão unidos em torno do mesmo ideário de trazer discussões sobre práticas alternativas de se construir a cidade, principalmente através da ressignificação dos espaços. A estratégia principal é chamar a atenção dos cidadãos para a possibilidade de usos diferenciados dos espaços públicos das grandes cidades e, de atrair olhares para tais espaços que, em alguns casos, encontram-se ociosos e, na maioria das vezes, esquecidos pelo poder público e pela sociedade. As atividades artísticas e culturais promovidas por estes grupos contribuem para a valorização do ideal de lazer, cultura e desenvolvimento de sociabilidades no ambiente urbano e para trazer uma nova atratividade às Praças. Isto acaba por proporcionar um novo dinamismo à vida social local, contrariamente ao que indicavam vários estudos.

Ao direcionar o foco para as atividades que aconteciam nas Praças pesquisadas, observou-se a presença de manifestações culturais que acompanhavam essa tendência, que envolvem a criação de novas modalidades de sociabilidade, graças à apropriação dos espaços públicos por grupos culturais de distintos formatos. Percebeu-se desde o início que o traço que unia esses grupos era a convicção da legitimidade da ocupação, voltada para a realização de distintas modalidades de eventos destinados a um público diferenciado, graças a uma forma de atuação alternativa, que reconhecia a positividade da sociabilidade e do convívio entre desiguais. Isto consolidou o foco da pesquisa nos processos de 
apropriação de usos realizados pelos atores sociais usuários das Praças, na busca de entender como constroem suas estratégias de apropriação dentro e fora desses lugares.

Com base nessas reflexões iniciais, percebeu-se que esse processo de apropriação do espaço público por grupos culturais, apontava para o delineamento de novas formas de ser e estar na cidade, como resultado de experiências e práticas sociais de construção da cidade que se quer. Trata-se de pensar o cotidiano, a apropriação social do espaço na sociedade urbana, como ações políticas e como parte de uma luta mais geral de acesso ao direito à cidade, que tem sido reivindicado ao longo das últimas décadas em variadas situações em diferentes cidades do mundo, utilizado num sentido mais amplo, que se distancia da formulação teórica original de Lefebvre (1968). No presente artigo, ainda que se recupere a perspectiva do autor quanto às potencialidades e desafios do direito à cidade, enquanto utopia possivel, em contraposição aos fundamentos da produção capitalista da cidade, adota-se aqui a concepção de direto à cidade, como um direito difuso a ser usufruído por todos que nela habitam. Significa dizer, como um direito sinalizador das possibilidades de transformação que reside no ideário de uma cidade para todos.

Cabe esclarecer que, para fins do presente artigo, trabalha-se com a ideia de espaço urbano, em sua dimensão de espaço socialmente construído, o que permite fazer uma aproximação com a concepção de território, tal como formulada por Santos (2007 a) - território usado ${ }^{3}$ Nesta direção, sustenta-se que são os grupos sociais, com suas formas de agir, de atuar e se relacionar em rede, que fornecem significados ao território. Significa dizer, que tanto a noção de território quanto a de espaço expressam a dimensão de construção social dos lugares. Assim, a ideia norteadora da pesquisa é mostrar os processos alternativos de produção dos espaços da cidade, enquanto espaços socialmente construídos.

Em outra perspectiva analítica compreende-se que a noção de campo de disputa pode auxiliar na compreensão das negociações e tensões presentes no processo de apropriação de uso das praças por distintos grupos sociais. Neste viés interpretativo, concebe-se Praça como espaço social, conforme o

\footnotetext{
${ }^{3}$ Para Santos (2007a:14) “o território tem que ser entendido como território usado, não o território em si. O território usado é o chão mais identidade".
} 
formula Bourdieu (1997:160), "um espaço formado por relações de proximidade e separação que são, antes de tudo, relações hierárquicas, configurando um campo, no qual diferentes disputas de distintos grupos se atualizam”. Numa sociedade hierarquizada, diz Bourdieu, não há espaço que não seja hierarquizado, que não exprima as hierarquias e as distâncias sociais de uma forma mais ou menos naturalizadas (1997:161).

Configura-se desse modo um campo de disputas, no qual, agentes públicos, instituições públicas, grandes empresas privadas, agentes do mercado imobiliário e financeiro constituem forças hegemônicas no embate com os movimentos de lideranças étnicas e religiosas, associação de moradores, grupos organizados de moradores contra remoções etc., que - como parte integrante desse embate - buscam organizar suas ações em confronto com a concepção de planejamento imposta. Essa dimensão da praça como um campo de disputa se configura no cotidiano das Praças estudadas.

Mesmo considerando que esses conflitos são implícitos aos processos de construção social do espaço e se manifestem em vários momentos como oposição de interesses, é possível identificar novas formas de apropriação de espaços públicos que inovam no sentido de modificar a concepção de ocupação espacial, qualquer que seja a demanda ou reivindicação que esteja em causa.

Por fim, deve-se mencionar que na reflexão e a na observação empírica dos processos de uso e apropriação privilegiou-se a abordagem qualitativa como recurso metodológico para identificar, tanto os usos derivados do ambiente urbano construído, que podem ser traduzidos como usos formais, como outras possibilidades de uso intuídas pelos usuários, identificados como usos informais, ou seja, adaptadas às necessidades imediatas ou aos desejos e intenções não satisfeitos na construção do ambiente (Mendonça:2007:298).

A seguir, focaliza-se a concepção de praça, seus usos e apropriações. Depois, apresentam-se as Praças selecionadas para estudo e os coletivos que nelas atuam e, finalmente, seguem-se os principais resultados de forma comparativa, bem como as considerações finais. 


\section{Praças: seus usos e apropriações}

Os espaços públicos integram a história territorial de formação das cidades desde a sua gênese, com transformações nas formas de concepção, uso e apropriação em consonância com os conteúdos da sociabilidade existente em cada período histórico considerado, assim, permitem entrever aspectos importantes para a compreensão da formação social, seus conflitos, resistências e resíduos (Burgos, 2016:6).

No debate atual sobre os espaços públicos a literatura aponta mudanças significativas em sua configuração, e destaca-se a ideia do declínio de sua função social. Novas discussões se fazem presentes e fica clara a necessidade de repensar e definir o modo de qualificar, como públicos, determinados espaços, de modo a contemplar não apenas a dimensão de espaço físico e urbano, mas também o das formas de sociabilidade e de convívio.

Sennett (1988), por exemplo, aponta para o esvaziamento da esfera pública em decorrência do isolamento do homem moderno, que se voltaria cada vez mais para a vida privada. Com isto haveria um desgaste significativo da vida pública. Isto porque, nas sociedades modernas as pessoas se tornariam cada vez mais individualistas, acabando por valorizar mais o lugar da intimidade em detrimento da vida pública.

Em suas definições mais usuais, as praças podem ser caracterizadas como espaços de uso comum, ou seja, acessíveis a todas as pessoas que vivem numa cidade e disponíveis às ações espontâneas dos indivíduos. São locais destinados a atender a atividades funcionais, sociais e/ou de lazer (Lynch, 1980).

Para fins deste estudo, as praças são entendidas como espaços urbanos públicos abertos, onde ocorrem as manifestações da vida urbana, projetadas com a finalidade de promover a convivência e a permanência das pessoas nesses locais. Segundo Sennett (1988), a praça surge como um dos elementos que reorganiza o espaço urbano, redefinindo os papéis sociais. 
A dimensão de apropriação pública da praça está presente na definição de Robba e Macedo (2002) no estudo sobre as praças brasileiras, que são concebidas como "espaços livres públicos urbanos destinados ao lazer e ao convívio da população, acessíveis aos cidadãos e livres de veículos" (2002, p.17).

Já para Mendonça a apropriação do lugar pode se configurar, tanto nas possibilidades de uso indicadas diretamente pelo ambiente urbano construído, ou ainda, nas possibilidades intuídas a partir dele, adaptadas às necessidades imediatas ou aos desejos e intenções não satisfeitas na construção do ambiente (2007: p.297).

Quando se reflete sobre a apropriação de espaços de uso coletivo, como a rua, por exemplo, é possível identificar modalidades especificas. Na etnografia sobre o bairro de Catumbi, no Rio de Janeiro, Santos e Vogel (1985) já observavam "a apropriação da rua como uma extensão da casa", particularmente no desenvolvimento das atividades cotidianas, nas brincadeiras infantis, nos encontros de vizinhos, nas festas, etc. Essas e outras formas específicas de apropriação do espaço público coletivo podem acontecer nas praças, bem como, outros modos particulares podem inovar e enriquecer a experiência de fruição do lugar. Isto porque, novas experiências somadas à flexibilidade de uso dos espaços públicos podem proporcionar mais vitalidade ao lugar.

Nesta direção, Mendonça (2007:297) destaca que a apropriação alternativa da rua revela ainda aspectos relativos à flexibilidade do uso dos espaços públicos, que podem sempre ser objeto de usos diferenciados, mesmo que formalmente constituídos para uma finalidade específica. Além disso, como diz a autora, apropriações do lugar não implicam em uso impróprio, pois, "mesmo quando intuídas e adaptadas não implicam, necessariamente, em inadequação ou indícios de marginalidade”. Ao contrário, tais apropriações "podem indicar criatividade, capacidade de melhor aproveitamento das infraestruturas públicas e fornecer subsídios que alimentem o projeto e a construção futura de ambientes desta natureza". Daí a importância de se investigar, diz a autora, as apropriações alternativas do espaço público, independente da existência, ou não, de infraestrutura específica para tal, seja para o exercício de atividades coletivas, seja para apropriação particular. 
Outro aspecto da apropriação de usos de espaços públicos é sua possibilidade de confronto com a atuação planejada do poder público. Nesta direção, Santos e Vogel (1985) atribuem a essas apropriações a função de "mecanismos de defesa e superação da população aos modelos urbanísticos impostos pela atuação planejada do poder público".

Aponta-se aqui, para um especial significado dos atos de apropriação, referido à sua capacidade de ampliar a compreensão dos desejos e das necessidades da população e seu respectivo vínculo ao ambiente urbano.

Pesquisas mais recente, como destacam Andrade, Jayme e Almeida (2009), referem-se às mudanças de configuração dos espaços públicos das grandes cidades, que incluem tanto os casos de privatização de ruas e praças, como ocorre nos condomínios fechados e bairros nobres da cidade (Caldeira, 2004; Andrade, 2003), em favelas e bairros dominados pelo tráfico de drogas (Souza, 2000); quanto para o uso de grades em torno de praças como estratégia para cercear esses espaços (Serpa, 2003). Alguns estudos apontam também para a diminuição do convívio social nos principais espaços públicos da cidade, substituído pela convivência em shopping centers (Pintaude, 1987; Pintaude\& Frúgoli, 1992; Padilha, 2006). É preciso lembrar que tais alterações são em parte decorrentes de um generalizado sentimento de insegurança e de medo, que dominam o meio urbano. Todas essas estratégicas têm gerado diversas interpretações, como por exemplo, a ideia do declínio dos espaços públicos e o predomínio de um individualismo exacerbado que prioriza a vida entre iguais em espaços vigiados e privatizados (Sennett, 1988; Davis, 1993; Augé, 1994; Serpa, 2003 e 2007).

De modo complementar, Santos e Vogel (1985), acima mencionados, apontam para a questão daqueles usos e das apropriações que não correspondem aos usos que o governo local definiu, que mostram outras possibilidades de se interagir nos espaços públicos. É importante trazer toda essa complexidade própria aos usos dos espaços públicos para mostrar que a cidade em sua dinâmica espacial abriga tanto espaços com declínio da vida urbana quanto aqueles que mostram grande dinamismo e vitalidade. 
Não se afirma aqui que o fenômeno de usos e apropriações se generaliza para todas as praças cidade, mas, sim, que pode ser entendida como uma tendência de forte constatação empírica nas duas Praças estudadas. Não se trata de identificar um conjunto homogêneo de lugares e sociabilidades, na medida em que existem praças de bairros, com uma sociabilidade bastante local; há ainda as das zonas centrais, como lugares de passagem para um grande número de pessoas, mas que são também de sobrevivência para outros. E, tantas outras praças espalhadas pela cidade, com suas singularidades. As rotinas desses espaços alteram-se segundo as horas do dia e os dias da semana, assim como o público. Deve-se lembrar ainda, que a intervenção do poder público, das associações de moradores e dos grupos locais são também fatores que influenciam a dinâmica dessas situações. Busca-se explorar todas estas questões a partir dos estudos de casos que apresentamos a seguir.

\section{Praça Marechal Maurício Cardoso}

Localizada na fronteira entre os bairros de Olaria e da Penha, a Praça Marechal Mauricio Cardoso, antiga Praça do Gari, situa-se entre o Clube do Olaria e o IAPI da Penha. Em seu entorno estão um supermercado (Extra), um Posto de Saúde, a Igreja de São Jorge e São Cosme e Damião, alguns edifícios e a biblioteca municipal. Pertence à área que se convencionou denominar de Grande Leopoldina, que abrange bairros significativos da Zona Norte do Rio: Vigário Geral, Parada de Lucas, Cordovil, Braz de Pina, Penha Circular, Penha, Olaria, Ramos, Bonsucesso, Manguinhos e Triagem. Ali já se localizaram importantes indústrias, que foram sendo desativadas. Algumas delas de importância econômica significativa a Curtume Carioca, a GE, a Gillete e a Cisper.

Pode-se dizer que o grande fator de mobilização dos moradores da região em relação à Praça ocorreu devido ao decreto de 2011 da Prefeitura, que alterava o uso de cinco praças nas Zonas Norte e Oeste, visando a instalação de Unidades de Pronto Atendimento (UPAs) nestes locais: Praça dos Lavradores, em Madureira; Praça Soldado Francisco Vitoriano, em Campo Grande; Praça Honoré de Balzac, em Senador Camará; Praça Santa Bárbara, em Rocha Miranda; e Praça Marechal Maurício Cardoso, em Olaria. 
Segundo os moradores entrevistados, "nós sentimos uma sensação de impotência", "ficamos sem entender, pois, ali próximo já existia um posto de saúde, cerca de uns 100 metros”. Não havia, portanto, segundo eles, razão para a construção de mais uma UPA naquela área, a não ser como disseram vários entrevistados que "fosse uma jogada política". Eles temiam a perda absoluta daquele espaço de lazer, ainda mais que já haviam perdido espaço com a instalação de uma cabine policial no local, em anos anteriores.

Um dos entrevistados mencionou que lembrava vagamente que o assunto fora apresentado em uma das reuniões da associação de moradores, mas apenas como uma possibilidade. Logo uma moradora, que é advogada, começou a estudar quais as vias que se poderia usar para tentar reverter aquele projeto que já estava em curso, haja vista os tapumes que estavam cercando a praça.

Além desse aspecto, os moradores destacavam que o projeto das UPAs é coordenado pelo Governo do Estado. Ou seja, a instalação das mesmas deveria ser feita em terreno estadual, e não num logradouro público municipal de uso comum do povo (conforme art.99, Cap.I do Código Civil). Por isso, diziam que uma maneira de viabilizar essa instalação seria utilizar imóveis estaduais sem uso, ou desapropriar imóveis para instalar as unidades de saúde. Assim, segundo os moradores, a utilização do espaço das praças do Município do Rio para a implantação das UPAs parecia implicar em uma "escolha de Sofia" imposta à população: ou se tem lazer público, ou se tem um posto de saúde.

Por outro, eles insistiam dizendo que "não havia sentido construir mais uma UPA ali, naquela região e que "lazer também é saúde" e que ambos são direitos sociais garantidos pelo art. $6^{0}$ da Constituição Federal, igualmente".

Com o apoio de uma advogada, que naquele momento era também vereadora do Partido Verde, os moradores entraram com uma representação contra a prefeitura alegando que os decretos do Prefeito agrediam, frontalmente, ao disposto no art.235 da Lei Orgânica do Município que diz: 
As áreas verdes, praças, parques, jardins e unidades de conservação são patrimônio público inalienável, sendo proibida sua concessão ou cessão, bem como qualquer atividade ou empreendimento público, ou privado que danifique ou altere suas características originais.

Deste modo, na representação apresentada ao Ministério Público os moradores da região insistiam que o governo municipal não podia impor a eles a política da escolha do "menos pior", pois todos são carentes de serviços de saúde, e também de áreas de lazer. Por outro lado, insistiam "o prefeito não podia simplesmente descumprir a Lei Orgânica do Município do Rio de Janeiro, extinguindo, paulatinamente, as praças públicas da Cidade, que se pretende Olímpica e Maravilhosa", como comentou um dos moradores.

Em todo o processo foi fundamental a atuação da então vereadora mencionada, que auxiliou o grupo até o momento em que ficou claro que não iriam mais construir a UPA no local.

Ao longo da luta de reivindicação contra a criação da UPA, os moradores mais atuantes passaram a se denominar como Grupo de Amigos e Defensores da Praça Marechal Maurício Cardoso. Em termos mais específicos, tratava-se da criação de uma estratégia, que se poderia chamar de modo bastante amplo de um tipo de associativismo, cuja reivindicação inicial de seus integrantes, além do fato já mencionado, era a discussão dos projetos da obra que estava acontecendo para a circulação do BRT, no trecho que vai da Penha ao Aeroporto do Galeão, ou seja, do corredor viário denominado Transcarioca. Os moradores começaram, então, a partir de 2011, a reivindicar maior participação na discussão e solicitaram a oportunidade de discutir o assunto em uma audiência pública na Alerj, na qual os participantes se apresentaram como "representantes de movimentos sociais atuantes nos bairros da Leopoldina”.

O coletivo avalia que obtiveram grande vitória, pois em seguida, com a ajuda da vereadora, que deu suporte jurídico ao abaixo assinado e ao recurso encaminhados ao Ministério Público, o decreto referente àquela praça específica foi sustado, sendo que o mesmo não ocorreu com as demais. 
O slogan utilizado e divulgado no jornal criado pelo grupo era: "Upa sim, na praça, não" e, assim, graças ao poder de mobilização e aglutinação de amigos e moradores dos bairros, conseguiu-se reverter a situação.

Desde o final de 2011, o grupo passou a direcionar suas atividades no intuito de ocupar social e culturalmente o espaço da Praça, reivindicando obras de revitalização. Hoje, entendem que seus objetivos são "ocupar a Praça por meio do desenvolvimento de atividades culturais e artísticas" e, com isso, fomentar a aproximação de seus moradores e valorizar a cultura local. Para isto, o grupo realiza uma série de atividades como comemoração do Dia Internacional da Mulher, Dia das Mães, Dia dos Namorados, Festa Junina, etc. O primeiro evento produzido pelo grupo foi a festa de Natal de 2011, patrocinada com recursos que seus integrantes conseguiram arrecadar e das tentativas de mobilização do comércio local, ainda que este segundo recurso não tenha se efetivado.

Tem sido fundamental acompanhar como este grupo vem construindo até hoje suas estratégias de atuação dentro e fora do espaço público da praça, bem como a questão acerca da ação coletiva, da cultura participativa, temas que merecem ser explorados para a compreensão da dinâmica das metrópoles. Sabe-se que as associações de moradores sempre ocuparam um papel importante tanto no campo dos movimentos sociais quanto no debate público sobre a cidade. Mas, as associações têm encontrado grande dificuldade para atuar no espaço público nos últimos anos, o que tem conduzido à criação de ações coletivas de outro formato, como é o caso estudado.

Segundo um dos membros do grupo, "para mim tinha o valor sentimental de preservar algo que sempre vivi, que sempre esteve presente na minha vida e que agora, de repente, ia se transformar em uma UPA". Isto talvez, admite o entrevistado, "tenha sido o mais forte, porque sempre tive a referência da praça ali. Nós iríamos perder a identidade da praça”.

O grupo foi o principal articulador para a criação da primeira feira orgânica daquela região, aliás, a única até hoje, que começou suas atividades em 2014. A ideia veio de um morador, consumidor de produtos sem agrotóxicos, que junto com voluntários e simpatizantes da causa da praça passou a 
coordenar a Feira Orgânica de Olaria em parceria com o coletivo Leopoldina Orgânica e a Feira de Artesanato da região. A proposta era "construir pontes entre a feira e os moradores", estimulando a "troca sobre alimentação", conforme nos disse o idealizador do projeto. Por isso mesmo, ele diz ter sido fundamental que os feirantes abraçassem a iniciativa e acreditassem na aproximação de novos consumidores.

Alguns integrantes do Grupo de Amigos e Defensores da Praça Mauricio Cardoso também ajudaram na realização do primeiro Fórum da Grande Leopoldina, projetado para se discutir questões voltadas para a melhoria da região. Até a presente data foram realizados sete eventos com este título e nestas ocasiões são debatidos temas como arte, cultura, ecologia, defesa do meio ambiente, enfim, questões que afetam à vida local. Para isso são convidados palestrantes de diferentes perfis que apresentam reflexões sobre os temas propostos pelo grupo.

Importante destacar que durante esses encontros, bem como durante a realização dos eventos de cunho mais festivos, sempre foi possível observar o intercambio e as trocas deste grupo com outros coletivos que atuam na cidade do Rio de Janeiro. Por exemplo, em um dos Fóruns, que pela primeira vez em 2014 foi realizado na própria praça, os anteriores haviam sido realizados no Clube do Olaria e na Unisuam, percebeu-se a presença de pessoas, que se apresentavam em nome de seus coletivos, com forte atuação na região da Grande Leopoldina, como o 100\% Suburbano, a Radio Bicuda, dentre outros.

Além disso, ao longo do trabalho de campo assistiu-se a diversas apresentações de diversos grupos culturais, que foram realizadas na praça, durante os diferentes eventos promovidos. Entre eles pode-se citar a Companhia Brasileira de Mystérios e Novidades, que atua na Praça da Harmonia, Dança Circular Sagrada, Grupo de Capoeira Terra Firme.

Enfim, a praça passou a ser um importante ponto de eventos culturais e encontro de artistas locais. Ali são apresentadas aulas de ioga, oficinas de alimentação, teatro infantil, contadores de histórias e apresentações musicais. Segundo um dos defensores da praça a ideia "é celebrar a coletividade". O 
local está sempre em movimento, pois os coletivos pensam aquele espaço de forma a proporcionar sempre uma maior integração entre as pessoas que ali circulam, promovendo ações socioambientais e culturais.

Percebe-se como o coletivo inicial coloca em evidência a noção de espaço público da praça a partir de uma perspectiva de uso comum, apontando para o fato de que a cidade deve ser compreendida como lugar da vivência compartilhada, da comunhão, da realização de atividades coletivas e de trocas entre grupos heterogêneos. Nisto reside a sua forma de atuar politicamente.

\section{Praça Harmonia}

Praça da Harmonia situa-se na Zona Portuária, área histórica de grande tradição cultural, religiosa, além de sindical, e vem sendo afetada pela reconfiguração de seu entorno, em nome de uma requalificação, que faz apelo aos anos de abandono que viveu a região. A principal tipicidade da Praça da Harmonia quanto à sua espacialidade é, portanto, estar no âmbito de atuação da Operação Urbana Consorciada Porto Maravilha ${ }^{4}$, operação esta dotada de forte legitimidade, devido à hospedagem dos megaeventos esportivos (Copa do Mundo/2014; Olimpíadas/ 2016), para os quais a cidade deveria se transformar em um cenário urbano renovado, de grande atratividade e competitividade, adaptado à lógica do capitalismo global (Sant'Anna e Pio; 2014).

A amplitude e a intensidade das intervenções geraram uma preocupação com o destino da Praça, tanto entre seus usuários e sua associação de moradores, como entre os grupos culturais que a ocupam. A reivindicação desses coletivos era a de que o lugar recebesse as melhorias necessárias e cuidados com sua conservação, mas que não fossem realizadas intervenções que envolvessem alterações na configuração do seu espaço.

\footnotetext{
${ }^{4}$ A Companhia de Desenvolvimento Urbano da Região do Porto do Rio de Janeiro/CDURP, é a gestora da prefeitura na Operação Urbana Consorciada Porto Maravilha, empresa pública de capital misto, tem como objetivo promover o desenvolvimento da Área de Especial Interesse Urbanístico/AEIU da Região do Porto do Rio de Janeiro. A Concessionária Porto Novo executa obras e serviços nessa Área de Especial Interesse Urbanístico/Aeiu.
} 
Constatou-se entre os usuários e grupos culturais e associação de moradores, em seu envolvimento com a Praça, uma recusa frente a intervenções urbanísticas, que afetassem o espaço do lugar, mudasse suas características e inviabilizasse suas atividades costumeiras.

Não havia uma definição efetiva quanto às obras que seriam implementadas na Praça devido a essa operação urbana. A CDURP e a Concessionária Porto Novo, não informavam exatamente o que iria ocorrer com a Praça, e a única referência que se encontra na proposta do Porto Maravilha é um mapa sobre espaços públicos, no qual, a Praça aparece como um espaço a ser ampliado, e uma indicação de que o entorno da Praça será beneficiado pelo VLT, planejado para ser o principal transporte da Região do Porto.

As mobilizações que ocorrem pela defesa da Praça da Harmonia não têm um caráter de movimento organizado com demandas específicas. A Associação de Moradores e Amigos da Gamboa/ AMAGA tem uma atuação, através de seu presidente e seus outros representantes, junto à Prefeitura, CDURP, Café Comunitário ${ }^{5}$, etc. A principal forma de luta pela a manutenção da Praça se expressa na ocupação efetiva do lugar, com atividades que podem ser incompatíveis com o modelo mercantilizado de cidade.

\section{Praça da Harmonia: os coletivos culturais estão chegando...}

Domingo de sol, agosto de 2015, a Praça Harmonia, no bairro da Gamboa, celebra a presença de Coletivos Culturais no seu espaço, em evento que comemorou o Dia Internacional da Mulher Negra Latino-Americana e Caribenha. Moradores da Gamboa e visitantes compartilharam atividades, como leituras de poemas, palestra, oficina de jongo e uma boa roda de samba ${ }^{6}$.

A presença de coletivos culturais na Praça é uma novidade relativamente recente, mas vem acontecendo com alguma regularidade. Os coletivos culturais representam uma nova forma de

\footnotetext{
${ }^{5}$ Reuniões "comunitárias" organizadas pelos comandos militares [que] possuem frequência mensal e costumam agrupar representantes de diferentes órgãos públicos, do setor privado e de organizações comunitárias, além de outros moradores e do comando da polícia (Davies, 2014, p. 28).

${ }^{6}$ Disponível em: https://www.brasildefato.com.br/node/32561, acesso em 29/06/2017
} 
apropriação do espaço da Praça Harmonia, ainda que o lugar já conviva há algum tempo, com manifestações culturais em seu espaço. São grupos culturais de defesa da arte de rua, mas que se estruturam de modo diferente e têm uma dinâmica de atuação diversa daquela dos coletivos culturais e, sua presença na Praça já ocorre há algumas décadas. Observou-se que, em comum, esses grupos e os coletivos culturais têm a defesa da arte de rua, e convicção de que a essência e função do espaço público está no seu caráter de local de trocas como cenário da diversidade e da democracia.

Quanto aos demais grupos culturais que ocupam a Praça muito antes da presença dos coletivos culturais, o Bloco Carnavalesco Cordão do Prata Preta é o que tem vínculo mais forte com o lugar; que faz parte de sua origem. Nasceu na própria Praça, em 2004, e ao longo de dez anos teve a Praça da Harmonia como "sua sede ao ar livre", como disse um dos diretores do Bloco, em entrevista. Hoje, o Bloco tem sua sede no Clube Filhos de Talma, na Rua do Propósito. O nome do Bloco é uma reverência a Horácio José da Silva, o Prata Preta, capoeirista e herói da Revolta da Vacina, que em 1904 mobilizou muitos moradores do bairro, contrários a vacinação obrigatória e em defesa de sua cultura e tradições, cujo confrontos aconteceram na Praça. Esse episódio histórico tem sua marca na Praça, em seu tradicional coreto, onde uma placa homenageia o herói Prata Preta.

O Bloco é responsável pelos ensaios pré-carnavalescos, e pelo próprio desfile de Carnaval. Concentrase na Praça e, quando realiza os eventos citados, ocupa todos os bares de seu entorno. Seu desfile percorre as pequenas e estreitas ruas do bairro, e volta para Praça para continuar a festa. Na entrevista com um dos diretores fica-se sabendo que o Bloco nasce do desejo de meninos, que como o entrevistado, cresceram no bairro e queriam ter seu próprio Bloco Carnavalesco, já que na vizinhança existiam outros blocos e ranchos. No Carnaval os bares do entorno da Praça são ocupados e tudo se junta à Praça.

Graças às observações realizadas em vários Carnavais foi possível constatar que se trata de um pequeno Bloco, com um pequeno número de músicos, que tocam no chão (não há carro de som) e que faz apelo ao carnaval tradicional, sempre com música e marchinhas antigas. Durante os eventos, em geral, o bloco reúne um público na faixa dos 30/40 anos, originários de bairros como Santa Tereza, 
vários bairros da zona sul e alguns bairros da zona norte, além dos moradores da Zona Portuária. Esse grande e diversificado contingente excede a capacidade das pequenas e estreitas ruas do entorno da Praça, onde acontecem os desfiles, o que preocupa a Diretoria do Bloco. Por sua vez, esta é uma das situações de uso e apropriação do lugar que mais marcam a identidade da Praça, fazendo-a conhecida em toda a cidade.

O Bloco começa e termina seu cortejo de Carnaval na Praça da Harmonia e, após uma semana, promove um novo evento carnavalesco: a batalha de confetes. Também organiza suas próprias festas juninas na Praça, além de outros eventos. Os diretores do Bloco e moradores do bairro afirmam com orgulho, que em 2014 o Prata Preta realizou a melhor festa junina que já ocorreu na Praça. Alguns dados são apresentados para comprovar tal entusiasmo. Conforme informa o site Monitor Digitaly ${ }^{7}$, foram cerca de quatro mil pessoas, em dois sábados, dançando forró, comendo comidas típicas e brincando nas barracas de jogos e brincadeiras, como pescaria, boca do palhaço e carrossel.

De fato, as festas juninas do Bloco atraem um público muito grande, que tem um perfil semelhante ao dos foliões do Carnaval do Prata Preta, ainda que com maior presença de crianças e de famílias da Zona Portuária. O sucesso da festa mostra que o evento ganha visibilidade a cada ano, com maior participação do público e de barraqueiros que apostam no sucesso do evento, o que nas primeiras festas juninas não ocorria.

É comum o Bloco desenvolver ações solidárias durante o evento, com a instalação de um posto de coleta que recebe doações de leite para bebês, e fraldas descartáveis, posteriormente entregues à Associação Reviver - Grupo de Apoio à Criança e ao Adolescente.

Outra presença importante e constante na Praça é a Grande Companhia Brasileira de Mystérios e Novidades, que se identifica como parte de um movimento cultural "que trabalha no risco e na busca do essencial do teatro". A Companhia afirma o Teatro de Rua como importante veículo de intervenção

\footnotetext{
${ }^{7}$ Disponível em https://monitordigital.com.br/prata-preta-o-maior-arrai-da-sa-de-ser-nesse-s-bado, acesso em 05/07/2017
} 
urbana e transformação, defende que arte pública tem potencialidade para fazer parte da cidade e a transformar, conforme o site de divulgação do grupo.

A Companhia atua em defesa da Arte de Rua, entendida como Arte Pública, arte para todos. Ela integra o coletivo ComDomínio Cultural de agentes culturais atuantes na zona portuária na construção de políticas públicas para a região, e faz parte também do Fórum Permanente de Arte Pública da cidade do Rio de Janeiro, liderado por Amir Haddad. Significa dizer, que a Companhia se situa politicamente e de modo coletivo na construção de sua proposta de uma arte para todos.

Nesse sentido a principal bandeira do grupo, é a própria defesa da Praça, na sua qualidade de espaço público, que deve se manter ali, para viabilizar os usos já apropriados e os novos usos que virão no usufruir da Praça como um espaço público coletivo.

A Companhia traz para a Praça ao longo de cada ano, seus espetáculos, com suas coreografias em pernas de pau e música ao vivo, trazidas pelos Gigantes Pela Própria Natureza que formam a Orquestra Itinerante de Rua sobre Pernas de Pau.

Ao longo do trabalho de campo foi possível observar e participar de várias festas, realizadas pela Companhia como Festas Juninas, Festa de Cosme e Damião, Festa de São João, O Dia Fora do Tempo, Cortejo dos Orixás, peças teatrais como o Uirapuru.

A Companhia além de se apresentar na Praça, tem também sua sede vizinha ao lugar, no casarão situado na Rua Pedro Ernesto 21, morada do grupo há 10 anos, o que a torna parte integrante do bairro da Gamboa. Em sua sede são apresentados vários tipos de espetáculos e sua agenda mostra programação anual e seu repertório atual com os espetáculos, entre eles: Pagode Brahmânico, A Saga de Jorge, Tão do Mundo, La Dolce Vita, Pajelança, Navelouca, Chegança do Almirante Negro, Uirapuru. Nos meses de maio e junho de 2017, fez parte de sua programação o espetáculo "Cabaré Mystico", além de série "Solos Ocupados", para comemorar 36 anos de trabalho voltado à arte de rua, com coreografias em pernas de pau e música ao vivo, inspirados na linguagem dos antigos atores e 
músicos populares. Nesses espetáculos os moradores da Região Portuária não pagam. O espetáculo teatral Uirapuru foi apresentado primeiramente na Praça Harmonia, e depois em várias outras cidades.

Este ano excepcionalmente, devido a cortes de orçamentos à cultura por parte da Prefeitura do Rio, a Companhia não pôde realizar sua festa junina na Praça, e assim foi substituída por uma festa na sua sede, que recebeu o nome de Pândanga Junina, festejada com muito forró.

Outra atividade cultural que vem acontecendo na Praça é o Festival Circuladô, que reforça a ideia de que a proposta de festas nas ruas está em alta e ganhando cada vez mais adeptos. A ideia agora é justamente resgatar as apresentações musicais que sempre deram vida aos coretos das praças.

Os Velhos Malandros é outro grupo cultural que também atua na Praça e tem como proposta revitalizar e resgatar a história do samba, para diferentes gerações e vertentes. Apresenta-se regularmente na Praça, convidando para suas apresentações artistas e representantes de comunidades afro-brasileiras. Em 2016 organizou e realizou na Praça, a IV Festa de Ogum, em homenagem a São Jorge.

Esse grupo realiza suas rodas de samba com regularidade e com muito público na Praça e, em algumas ocasiões, apresenta-se junto à Feira de Arte e Cultura Amigos da Harmonia.

Esse evento realizado pela AMAGA com um grupo de artesãos e artistas, acontece todo segundo sábado do mês. Seus organizadores e expositores consideram que "ocupar a Praça com a Feira é um ato de resistência". Algumas barracas de artesanato expõem e vendem seus produtos e, nestas ocasiões são desenvolvidas também atividades lúdicas programadas para as crianças. De forma mais esporádica acontecem pequenas oficinas de bordado, de costura, etc. É de fato uma rotina para marcar presença no lugar até que terminadas as obras, a Feira se torne novamente um lugar de fácil acesso, com a expectativa de que o VLT viabilize essa tarefa. O importante é que a Feira não deixou de existir, nem mesmo nos momentos mais difíceis nos quais o grande número de obras no bairro fechava ruas, 
mudava o trajeto do ônibus e trocava as direções das vias. Mesmo nesse quadro desfavorável, que inviabilizava o acesso ao bairro e à Praça, a feira estava ali presente. Hoje conta com o VLT para dinamizar e trazer mais pessoas à Feira.

A Praça recebe ainda outras rodas de samba como a do grupo Samba Independente dos Bons Costumes, que conta com a presença de diferentes grupos de sambistas São eventos com características muito locais, embora contem com a presença de moradores de outras áreas da cidade.

Pode-se perceber que a atuação desses grupos sociais reside na produção de ações alternativas na forma de produzir a cidade. Por meio de suas ações e práticas vemos um incremento na vida cultural da localidade, procurando fortalecer os laços entre moradores locais, da Zona Portuária e de outros bairros da cidade, estimulando assim novas formas de sociabilidade e a relação de um público mais amplo com o território.

Quanto aos grupos culturais que atuam em ambas as Praças, deve-se ressaltar que acontecem parcerias com aqueles grupos que atuam em locais distintos aos das Praças, e mesmo com aqueles que constituem suas redes. Outra questão a lembrar é que o convívio entre eles e internamente a cada grupo nem sempre é harmonioso, existem disputas negociações, tensões e conflitos, que não são objeto de discussão no presente artigo.

\section{As Praças e seus lugares no espaço da cidade: considerações finais}

Com localização diferenciada no espaço da cidade, as duas Praças pesquisadas convivem com lógicas espaciais igualmente distintas. As singularidades de cada local decorrem, em parte, de seu lugar no território da cidade. Quanto à suas semelhanças, elas estão mais ligadas ao lugar que ocupam no espaço da cidade, no sentido de incorporar tendências que acontecem na cidade como um todo.

Como antes mencionado, a localização Praça da Harmonia na zona portuária lhe traz a peculiaridade de ser parte e conviver com transformações trazidas pela Operação Urbana do Porto Maravilha. A 
Praça Mauricio Cardoso situa-se na Zona Norte da cidade; sua particularidade advém de sua inserção espacial na Grande Leopoldina, importante área da cidade que vem merecendo atenção especial quanto a seu planejamento urbano e de revitalização das atividades industriais e de serviços, que já caracterizaram a dinâmica econômica do lugar.

Ao longo do trabalho procurou-se chamar a atenção para as novas formas de uso e apropriação do espaço público que acontecem em ambas as Praças, localizadas na cidade do Rio de Janeiro, demarcadas fundamentalmente pela atuação de grupos culturais, com uma lógica de intervenção no espaço urbano de dimensão também política, dada fundamentalmente por suas presenças efetivas no lugar. O ato de estar no espaço público é político em si mesmo. Essa presença construída no cotidiano dos espaços públicos permitiu perceber o processo de construção social do espaço.

Tais coletivos têm em comum a valorização do uso do espaço público e uma ação pautada pela ideia de direito à cidade. A partir de um novo ângulo, o da promoção de eventos que aglutinam moradores de bairros distintos e movidos pela intensa criatividade, esses grupos reafirmam a positividade da sociabilidade urbana e do convívio entre desiguais. Com isso, observou-se como novas modalidades de sociabilidade podem vir ressignificando os espaços públicos, derivadas de novas formas de apropriação do espaço, como ocorre em ambas as Praças.

Os grupos culturais adotam diferentes estratégias de atuação, sejam artísticas, culturais e políticas, como forma de ativar a vida urbana em suas múltiplas dimensões, particularmente ao questionarem o caráter centralizador com que são conduzidas as políticas públicas. Por isso, é fundamental entender como estas formas coletivas de ação derivam de um conjunto de contradições manifestas no espaço físico e existencial das cidades. E, que elas podem ser entendidas como novas formas de ação que têm também uma dimensão política. São novas modalidades associativas de intervenção urbana que possibilitam que seja ampliado o repertório de leituras possíveis sobre os territórios.

Procurou-se assim problematizar os processos alternativos de produção dos espaços da cidade enquanto espaços socialmente construídos, com base nos dois estudos de casos realizados. As ações e 
práticas desenvolvidas pelos grupos que atuam nas Praças mostram o contraponto da ideia de que os espaços públicos perderam sua potencialidade de troca, interação, diversidade e convívio. De certa maneira eles buscam resgatar a função vista como primordial do espaço público, de local de troca, como cenário da diversidade, do diálogo e da democracia.

Para Leite (2002) o espaço público se configura qualificando um logradouro público justamente na confluência entre espaço concreto e material da rua e as ações sociais que lhe dão sentido. Por isso, as práticas desencadeadas pelos coletivos que atuam nas Praças é que qualificam o espaço público. Nesta perspectiva, os casos aqui apresentados poderiam ilustrar sua concepção de contra-usos.

Sinaliza-se, enfim, para as possibilidades de edificação de novas formas de ser e estar na cidade, derivadas de experiências e práticas sociais coletivas, que buscam a criação da cidade que se quer. 0 direito à cidade se constituindo, assim, em indicador das expectativas de transformações próprias ao ideário de construção de uma cidade para todos.

\section{REFERÊNCIAS}

ANDRADE, L.T.; JAYME, J. G.; ALMEIDA, R. C. Espaços públicos: novas sociabilidades, novos controles. Cadernos Metrópole, São Paulo, v. 21, pp. 131-153. 2009.

ANDRADE, L.T. Segregação socioespacial e construção de identidades urbanas. In: MENDONÇA, J.G.\&GODINHO, M.H. de L. (orgs.) População, espaço e gestão na metrópole. Belo Horizonte, PUC-Minas, 2003, pp.59-72.

AUGÉ, M. Não lugares: introdução a uma antropologia da supermodernidade. Campinas: Papirus, 1994. 111p.

BOURDiEU, P. Efeitos do lugar. In: BORDIEU, P. (org.) A miséria do mundo. Rio de Janeiro: Vozes, 1997.

BURgos, Rosalina. Direito à Cidade: Utopia Possível a partir do Uso e Apropriação dos Espaços Públicos Urbanos. XIV Coloquio Internacional de Geocrítica Las utopías y la construcción de la sociedad del futuro. Barcelona. Barcelona, 2-7 de mayo de 2016

CALDEIRA, T. P. do R. Cidade de muros: crime, segregação e cidadania em São Paulo. São Paulo: Edusp, 2004. 399p.

CDURP - Instituto Pereira Passos. Estudo de impacto de vizinhança - Operação Urbana Consorciada da Região do Porto do Rio. 441 p. 2010. Disponível em:

http://p-web01.mp.rj.gov.br/Arquivos/RAP/EIV.pdf

DAVIES, Frank Andrew. (2014), "Rituais de 'pacificação': Uma análise das reuniões organizadas pelos comandos das UPPs”. Revista Brasileira de Segurança Pública, Vol. 8, nº 1, pp. 24-46. 
DAVIS, M. Cidade de quartzo: escavando o futuro em Los Angeles. São Paulo, Scritta, 1993, 378 p.

GONÇALVES, P. M. R. Rua Sacadura Cabral e zona portuária. Revista do Arquivo Geral da Cidade do Rio de Janeiro, Rio de Janeiro, n.6, 2012, pp.231-246.

HOLLANDA, Heloisa B. de Coletivos. Disponível em:

http://www.heloisabuarquedehollanda.com.br/coletivos/ acesso em 01/08/17

LEFEBVRE, H., Le droit à la ville, Paris, Éditions Anthropos, 1968, 164 pages.

LEITE, R. P. Contra-usos e espaço público: notas sobre a construção social dos lugares na Manguetown. Revista Brasileira de Ciências Sociais, São Paulo, v. 17, n. 49, p. 115-134. 2002.

LYNCH, Kevin. A imagem da cidade. São Paulo: Martins Fontes, 1980, 240p.

MENDONÇA, E. M. S. Apropriações do espaço público: alguns conceitos. Estudos e Pesquisas em Psicologia, Rio de Janeiro, v. 7, n. 2, 2007, pp. 296-306.

PADILHA, Valquíria. Shopping Center: a catedral das mercadorias e do lazer retificado. Campinas: [s.n.], 2003, 209p.

PINTAUDE, S. M. Os shoppings centers brasileiros e o processo de valorização do espaço urbano. Boletim Paulista de Geografia, São Paulo, n. 65, 1987, pp. 29-48.

PINTAUDI, S.M. \& JR. FRUGOLI H., Shopping Centers - Espaço, Cultura e Modernidade nas Cidades Brasileiras, São Paulo: ed. Universidade Estadual Paulista,1992, 129p.

ROBBA, F; MACEDO, S.S. Praças Brasileiras: public squares in Brazil. São Paulo: Edusp, 2002, 311p.

SANT'ANNA, M. J. G.; PIO, L. G. Megaeventos Esportivos, Dinâmica Urbana e Conflitos Sociais: Intervenções Urbanas e Novo Desenho para a Cidade do Rio de Janeiro. In: SANTOS, A. M. S. P; SANT'ANNA, M. J. G. (Orgs). Transformações territoriais no Rio de Janeiro do século XXI. Rio de Janeiro: Gramma: Faperj, 2014. 103-122.

SANTOS, M. O Espaço do Cidadão, 7. ed. São Paulo: Edusp, 2007, 176p.

SANTOS, M. O dinheiro e o território. In: SANTOS et al. Território, territórios: ensaio sobre o ordenamento territorial. Rio de Janeiro: Lamparina, 2007a, 416p.

SANTOS, C. N. dos, VOGEL, A. Quando a rua vira casa: a apropriação de espaços de uso coletivo em um centro de bairro. 3 ed. São Paulo: Projeto,1985, 149 p.

SENNETT, R. 0 declínio do homem público: as tiranias da intimidade. São Paulo: Cia. das Letras, 1988, 532p.

SERPA, A. S. P. 0 espaço público na cidade contemporânea. São Paulo: Editora Contexto, 2007, 208p.

SERPA, A. S. P. Apropriação social versus requalificação dos parques e praças na capital baiana. In: ESTEVES JR., M. e URIARTE, U. M. (Orgs). Panoramas urbanos: reflexões sobre a cidade. Salvador: EDUFBA, 2003, p. 121-139.

SOUZA, M. L. de. 0 desafio metropolitano: um estudo sobre a problemática sócio-espacial nas metrópoles brasileiras. Rio de Janeiro, Bertrand Brasil, 2000, 360p. 